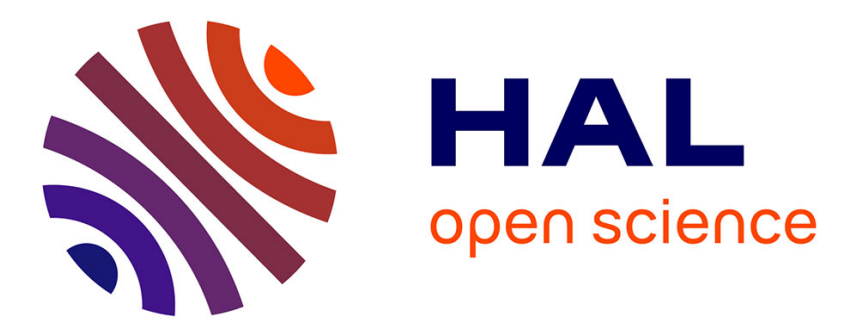

\title{
Acetylene pyrolysis in a jet-stirred-reactor for low pressure gas carburizing process- Experiments, kinetic modeling and mixing intensity investigations by CFD simulation
}

\author{
Tsilla Bensabath, Hubert Monnier, Pierre-Alexandre Glaude
}

\section{To cite this version:}

Tsilla Bensabath, Hubert Monnier, Pierre-Alexandre Glaude. Acetylene pyrolysis in a jet-stirredreactor for low pressure gas carburizing process- Experiments, kinetic modeling and mixing intensity investigations by CFD simulation. Chemical Engineering Science, 2019, 195, pp.810-819. 10.1016/j.ces.2018.10.028 . hal-02139125

\section{HAL Id: hal-02139125 \\ https://hal.science/hal-02139125}

Submitted on 24 May 2019

HAL is a multi-disciplinary open access archive for the deposit and dissemination of scientific research documents, whether they are published or not. The documents may come from teaching and research institutions in France or abroad, or from public or private research centers.
L'archive ouverte pluridisciplinaire HAL, est destinée au dépôt et à la diffusion de documents scientifiques de niveau recherche, publiés ou non, émanant des établissements d'enseignement et de recherche français ou étrangers, des laboratoires publics ou privés. 


\title{
Acetylene pyrolysis in a jet-stirred-reactor for low pressure gas carburizing process-
} Experiments, kinetic modeling and mixing intensity investigations by CFD simulation Tsilla Bensabath $^{1,2}$, Hubert Monnier ${ }^{1 *}$, Pierre-Alexandre Glaude ${ }^{2}$

${ }^{1}$ Institut National de Recherche et de Sécurité, 1, rue du Morvan, 54519 Vandœuvre-lès-Nancy, France

${ }^{2}$ Laboratoire Réactions et Génie des Procédés, CNRS, Université de Lorraine, 1, rue Grandville, 54000 Nancy, France

*Corresponding author: hubert.monnier@inrs.fr

\section{Highlights}

- Pyrolysis experiments to study formation of $\mathrm{H}_{2}$ to $\mathrm{C}_{7}$ during gas carburizing conditions.

- CFD simulations characterizing the hydrodynamics of a continuous stirred tank reactor.

- Comparison of experimental light hydrocarbon formation and that predicted by a kinetic model.

\begin{abstract}
Low-pressure gas carburizing is used to harden steel, it has been shown to be a source of considerable PAH (Polycyclic Aromatic Hydrocarbon) pollution. Some PAH, like benzo[a]pyrene, are carcinogenic, and activities such as furnace maintenance and cleaning operations may thus represent a risk to workers. Occupational exposure during these operations should therefore be reduced. Benzene is a specific chemical marker of PAH, and the aim of the study was to understand its formation. Acetylene pyrolysis was experimentally performed in a jet-stirred-reactor in the laboratory, in conditions close to those encountered in industrial processes $(1173 \mathrm{~K}$ and $8 \mathrm{kPa})$. Products of pyrolysis were analyzed by gas chromatography (TCD, FID) at the outlet from the reaction zone. The influence of residence time in the reactor was studied. A detailed kinetic model assuming an ideal continuous stirred tank reactor was used to describe the formation of chemical compounds and validate experimental data. CFD simulations were performed to characterize the
\end{abstract}


reactor's hydrodynamics by applying the theory of the free jet. They allowed putting forward one explanation to understand the deviation between experiments and the kinetic model.
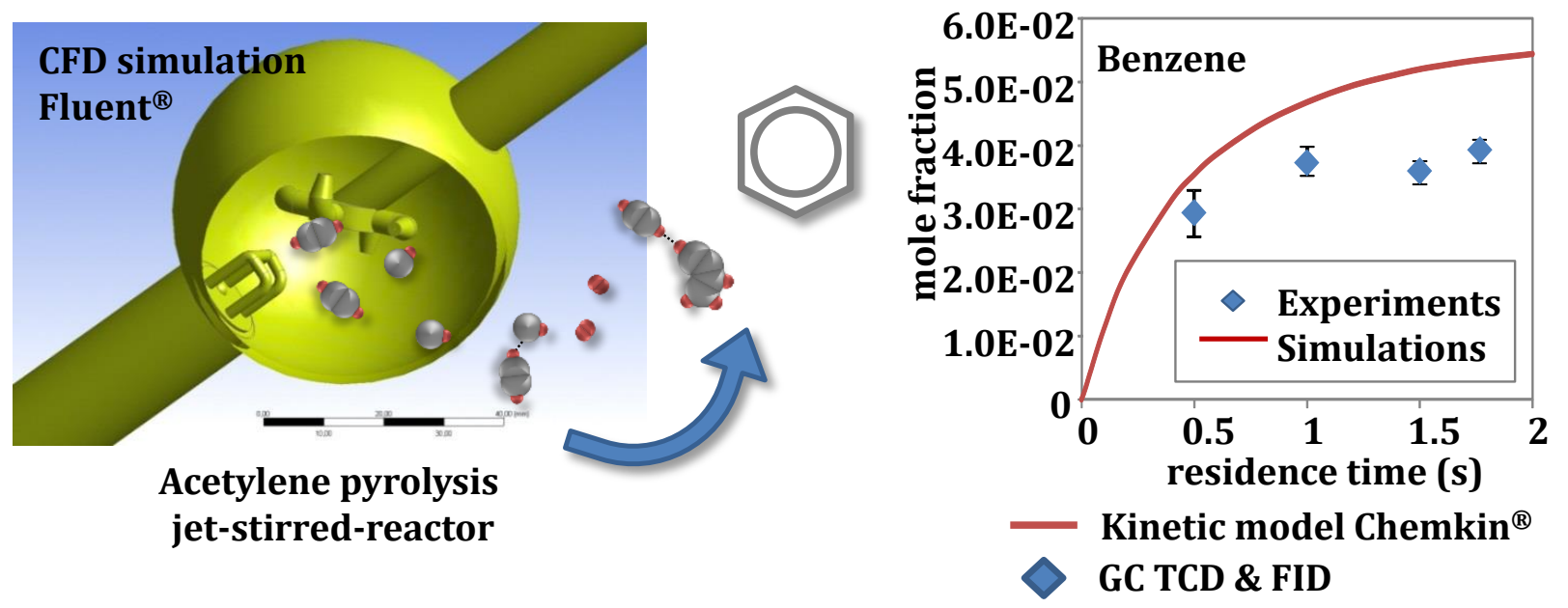

Keywords: Pyrolysis, Acetylene, carburizing, jet-stirred-reactor, mixing, CFD

\section{Introduction}

Low-pressure carburizing is performed in a vacuum furnace using hydrocarbon gases at high temperatures. This heat treatment is used to increase the surface hardness of steel by incorporating carbon atoms. Chemical reactions at the surface occur between some hydrocarbons, such as acetylene (Yan et al., 2012; Dai et al., 1999), or free radicals. Atomic carbon is formed and diffuses within the steel raising the superficial content to between 0.7 and $0.9 \%$ wt (Hiep and Kaliaguine, 1973; Iwata, 2005; Dulcy and Gantois, 2007). Hydrogen (or hydrogen radicals) remains blocked in the pores or is released in the gas phase. Simultaneously, gas phase pyrolysis occurs. As a result, the by-products to this process include Polycyclic Aromatic Hydrocarbons (PAH), many of which are carcinogenic substances, such as benzo[a]pyrene (BaP) (IARC, 2012). These by-products condense as soot or tar mainly in exhaust pipes or cold zones in the reactor (Champmartin et al., 2017). During maintenance and cleaning operations, workers can be exposed to these substances by inhalation and skin contact. 
The aim of this study was to understand the pathways through which chemical compounds form to identify operating conditions improving occupational risk prevention when using the low-pressure gas carburizing process. This work showed how residence time affects the formation of hydrocarbon species like benzene, which is a carcinogenic chemical indicator of PAH generation, at $1173 \mathrm{~K}$ and $8 \mathrm{kPa}$ (pyrolysis conditions encountered during the carburizing processes).

To study gas pyrolysis, laboratories perform experiments in gas-jet stirred-reactors, JSRs (Matras and Villermaux, 1973; Rota et al., 1994; Herbinet et al., 2015; Hognona et al., 2018). The main advantage of this set-up is probably the homogenous interior make-up, thanks to its spherical shape and its four nozzles, which allows it to be considered to be a perfectly stirred reactor. This assumption considerably facilitates modeling of JSR. Kinetic models have been developed, and their results can be compared to experimental data. Our experiments were carried out with the JSR and results obtained with the detailed kinetic model published elsewhere were finally compared to our experimental results (Bensabath et al., 2016).

However, the ideal flow pattern within the continuous JSR may only be valid for a certain range of process conditions. If operating conditions - such as temperature, pressure or compounds used - are changed, the hydrodynamic conditions may be modified (Herbinet and Dayma, 2013; Ayass et al., 2016). Thus, discrepancies between experimental and model results can be observed due to an invalid assumption.

Therefore computational fluid dynamics (CFD) simulations were conducted to explain the deviation between experiments and the kinetic model. The aim was to characterize the reactor's hydrodynamics by applying the theory of the free jet (Commenge, et al., 2006; Gavi et al., 2007; Adeosun and Lawal, 2009; Kanaris and Mouza , 2011; Woldemariam et al., 2016).

\section{Materials and methods}

\subsection{Jet-stirred-reactor characteristics}


The JSR used for the experimental study was composed of a sphere and two pipes (Figure 1). The sphere is the reactor, which is assumed to be perfectly stirred. The pipes transport acetylene to the sphere and are used to remove products as quickly as possible to prevent chemical reactions occurring in the pipes. To reduce the residence time of chemical compounds in the pipes and to increase their velocity, acetylene and products are displaced through annular spaces. The high surface/volume ratio is the annular zone allows also the preheating of the reactants up to the reactor temperature to avoid temperature inhomogeneity (Azay and Côme, 1979). Chemical reactions occur in the sphere where gas is injected from four different directions through nozzles placed as shown in Figure 2. Hilgers and Boersma (2001) have used numerical simulation to enhance mixing in the jet. They have combined direct numerical simulation of an incompressible jet flow with stochastic optimization procedures. They found that a combined axial and helical actuation is much more efficient with respect to jet mixing than a helical actuation alone. This work confirms the particular shape of the four nozzles separated by a $90^{\circ}$ angle.

The body of the JSR is made of quartz to allow its use at $1173 \mathrm{~K}$. To study the carburizing process, a quartz support was made to place a piece of iron inside the reactor. Carburizing of this piece will not be discussed in this article, but the presence of the support can affect the reactor's hydrodynamics.

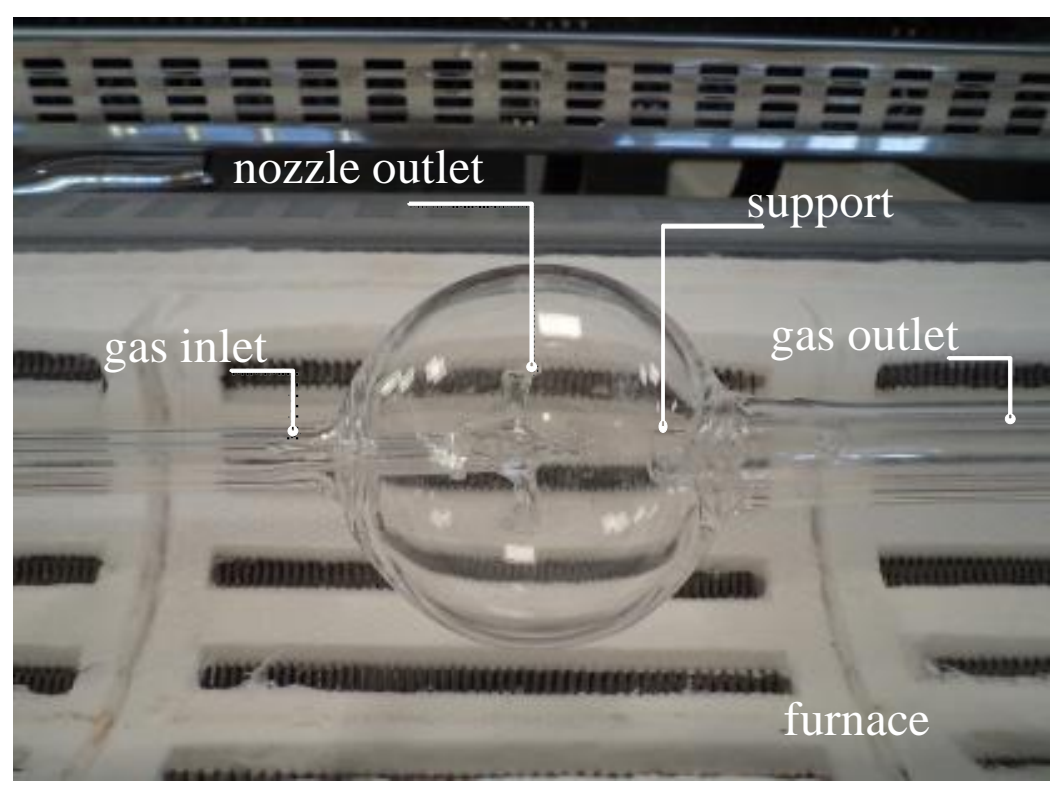

Page 4 
Figure 1: Picture of JSR in a furnace with its four nozzles, a support to place a piece of iron and two pipes with an annular space for inlet and outlet gas- quartz parts made by VERAL, Colombes, France (Matras and Villermaux, 1973)

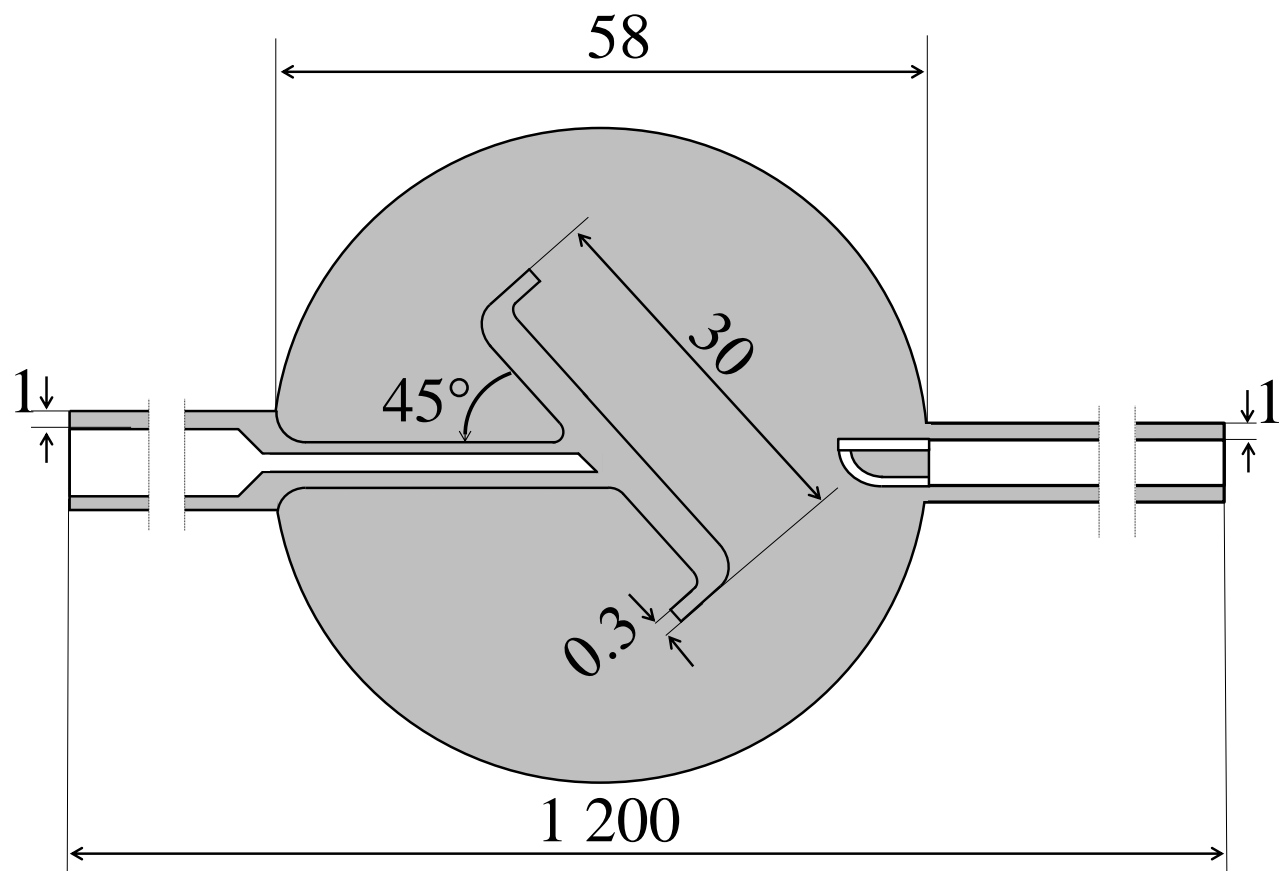

Figure 2: Diagram of a JSR fitted with a support for placement of an iron piece to be carburized -

Four nozzles separated by a $90^{\circ}$ angle - outlet nozzle diameter is close to $\mathrm{d}_{\text {nozzle }}=300 \mu \mathrm{m}$, $\mathrm{V}_{\text {sphere }} \approx 100 \mathrm{~mL}, \mathrm{~S}_{\text {nozzle }}=0.07 \mathrm{~mm}^{2}($ Matras and Villermaux, 1973)

The hydrodynamics of the JSR have been studied at room temperature, atmospheric pressure and with air or argon (Herbinet and Dayma, 2013; Ayass et al., 2016). Three hydrodynamic conditions must be considered to allow it to be considered like a perfectly stirred reactor (David and Matras, 1975; Hinze and Van der Hegge Zijnen, 1949).

(1) The jet at the nozzle exit must be turbulent. As a result, there is a lower limit for the Reynolds number (Eq. 1, Figure 3):

$$
\operatorname{Re}_{j e t}=\frac{4 \rho A R^{3}}{6 \mu d \tau \tan \beta}
$$


which will satisfy the following inequality:

$$
\frac{A R^{3} \rho}{d \tau \mu} \geq 230
$$

(2) The four jets from the nozzles must mix all the fluid within the sphere. This requirement is expressed as a condition relating to the recycling rate, and produces the following inequality:

$$
\frac{A R}{d}>19
$$

(3) The gas velocity at the outlet of nozzles must remain below the speed of sound, which depends on $\mathrm{T}$ and $\mathrm{P}$.

$$
\frac{4}{3} \frac{R^{3}}{d^{2} \tau} \leq c_{\text {sound }}(T, P)
$$

The A parameter is a dimensionless constant influenced by $\mathrm{T}$ and $\mathrm{P}$, it can be experimentally determined by applying the theory of the free jet (Hinze and Van der Hegge Zijnen, 1949). This parameter characterizes the distribution of gas velocity along the axis of the jet exiting a nozzle as a function of the distance to the nozzle outlet and the nozzle diameter required for good recirculation (Figure 3). The jet is assumed to be free if the criterion in (Eq. 5) is satisfied:

$$
\frac{2 \pi}{3} \frac{\rho R^{4}}{\tau d^{2} \mu} \geq 710^{-4}
$$

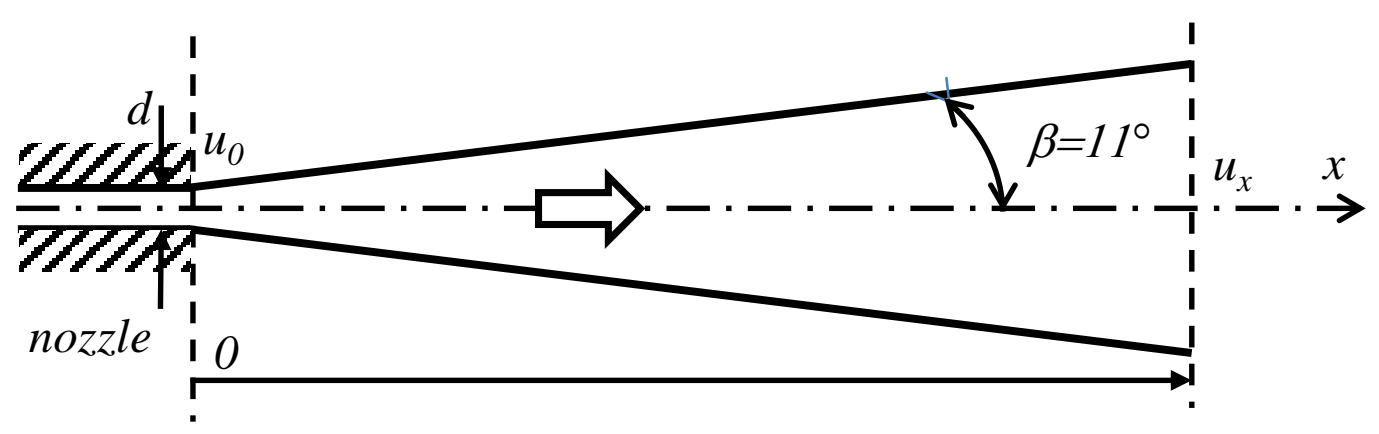

Figure 3: Diagram of the gas cone at the nozzle outlet representing the hypothesis of the free jet (Hinze and Van der Hegge Zijnen, 1949) 
Hinze and Van der Hegge Zijnen (1949) experimentally determined Eq. 6 at $293 \mathrm{~K}, 101.3 \mathrm{kPa}$ under air:

$$
\frac{u_{x}}{u_{0}}=6.39\left(\frac{d}{x+0.6 d}\right)
$$

This condition can be simplified if the opening angle of the jet is $22^{\circ}$ and $x>10 d$ (Eq. 7) (Bush, 1969).

$$
\frac{u_{x}}{u_{0}}=6.39\left(\frac{d}{x}\right)
$$

Integration of the gas velocity over the section gives the volume flow rate and produces the following equation (Eq.8) (Matras and Villermaux, 1973):

$$
\frac{Q_{x}}{Q_{0}}=A\left(\frac{x}{d}\right) \text { with } A=0.3 \text { at } 293 \mathrm{~K}, 101.3 \mathrm{kPa} \text { under air }
$$

Thus, depending on $\mathrm{T}$ and $\mathrm{P}$, the $\mathrm{A}$ and $c_{\text {sound }}$ parameters vary, and consequently change the three operating conditions (Herbinet and Dayma, 2013; Ayass et al., 2016). Because pyrolysis reactions occur at high temperature, at low-pressure and in the absence of air it appears important to investigate how these parameters influence the three criteria described above. In addition, experimental hydrodynamic measurements are very difficult to perform in these conditions. Therefore, CFD simulations were performed to characterize the hydrodynamics of the reactor to confirm the hypothesis of perfect mixing at high temperature and under vacuum pressure.

\subsection{Experimental set-up}

Acetylene pyrolysis experiments were performed in the experimental set-up shown in figure 4. This set-up consists of a gas inlet, a reaction chamber, an on-line gas analysis system. Low-pressure (8 $\mathrm{kPa}$ ) was attained using a rotary vane pump (Edwards E1M18 Atex 3), and controlled thanks to a 
solenoid control valve (MKS 0248A) and absolute pressure transducers (MKS Baratron ${ }^{\circledR}$ 622B). Gases (acetylene and nitrogen) were contained in gas cylinders (Air Liquide and Air Products ${ }^{\circledR}$ ) and flow rates were adjusted by mass flow controllers (Brooks ${ }^{\circledR}$ SLA 5850S). Nitrogen, as an inert gas, was used to exclude air, in particular oxygen, from the experimental set-up. A single controller was sufficient to produce acetylene flow at between $64 \mathrm{NmL} \cdot \mathrm{min}^{-1}$ and $225 \mathrm{NmL} \cdot \mathrm{min}^{-1}$ to allow the study of the influence of the residence time (between $1.75 \mathrm{~s}$ and $0.5 \mathrm{~s}$, respectively) for the gas. The reactor was positioned horizontally, with the sphere centered, in a tubular three-area furnace (Carbolite $^{\circledR}$ HZS 12/600). Rigid Inox ${ }^{\circledR}$ pipes were connected to quartz parts using flexible connectors from Swagelok ${ }^{\circledR}$, Neyco ${ }^{\circledR}$ and Oerlikon Leybold Vacuum.

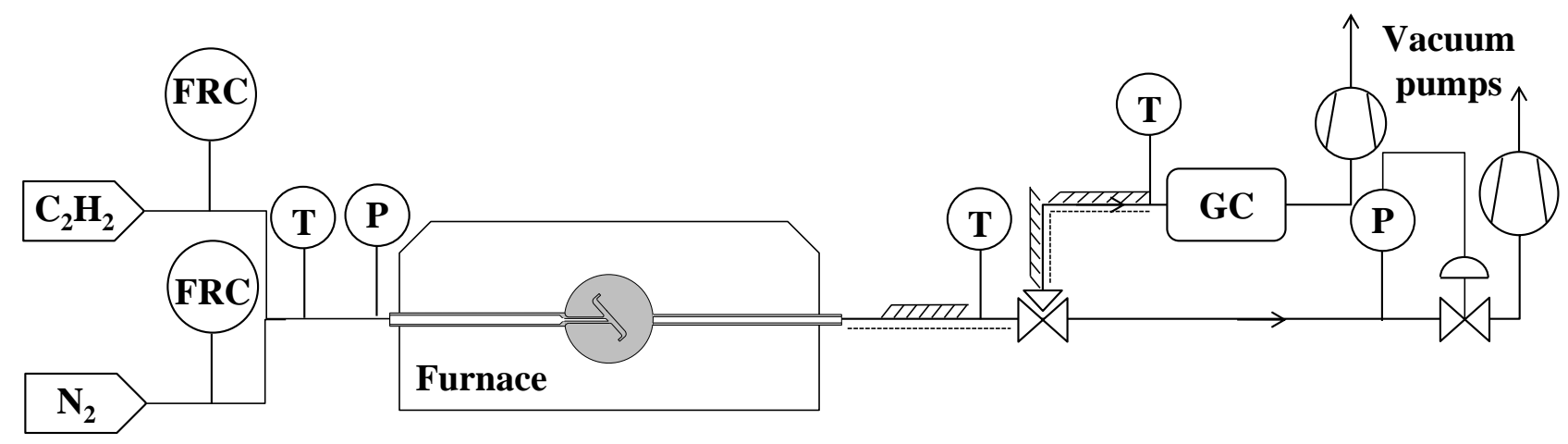

Figure 4: Experimental set-up (-------- heating flex; 7777 insulation; T: temperature sensor; P:

pressure sensor; FRC: mass flow controller) - Products were analyzed on-line by gas chromatography thanks to a vacuum pump, two sampling loops and five column (see supplementary data)

Products were analyzed on-line by gas chromatography (PerkinElmer, Clarus 580 GC, adapted by Antelia; described in supplementary information). The GC was fitted with two sampling loops (Bensabath, 2017). The two loops fill simultaneously during gas sampling which was performed under vacuum by means of a pump located downstream of the GC. The first loop and column are connected to a thermal conductivity detector (TCD) to quantified hydrogen. The second circuit leads to a flame ionization detector (FID) to quantified hydrocarbons up to toluene. Before analysis, 
a nitrogen plug-flow compression system was used to adjust the pressure in the sampling loops to 1.1 bar. The aim of this operation was to ensure that the amount of material in the loops was the same for all analyses, whatever the operating conditions applied. The volume and temperature of the loops were maintained constant. At the beginning of analysis, the gas was simultaneously sent into two parallel circuits. Hydrogen is quantified by the TCD whereas the FID allows the speciation of methane, ethylene, acetylene, 1,3-butadiene, propyne, vinylacetylene, benzene and toluene. The accuracy of analyzes is evaluated at $10 \%$ for the reactant and at $15 \%$ for minor species.

2.3. Degree of thermal homogeneity of the reactor.

To perform CFD simulation and to avoid using the energy equation, the degree of thermal homogeneity of the reactor was studied to assess the isothermal assumption. In order to ensure that these temperature measurements have been carried out to determine the gap between the set point temperature of the furnace (three temperatures) and the reactor (and the two pipes) temperature, figures 5 and 6 respectively. The $\mathrm{K}$ type thermocouple technology is used because it accuracy at high temperatures close to $1173 \mathrm{~K}$ is better than a Pt100. The sensor is connected to the ALHBORN ${ }^{\circledR}$ precision measuring instrument. The gap between the set point temperature around $1173 \mathrm{~K}$ and the reactor (sphere and two pipes) is below $1 \%$ thanks to two other electrical resistances placed on both ends of the furnace to prevent heat losses. Therefore calculations and experiments supposed that on the one hand the JSR is isotherm and the other it temperature is equal to the set point temperature of the furnace. 


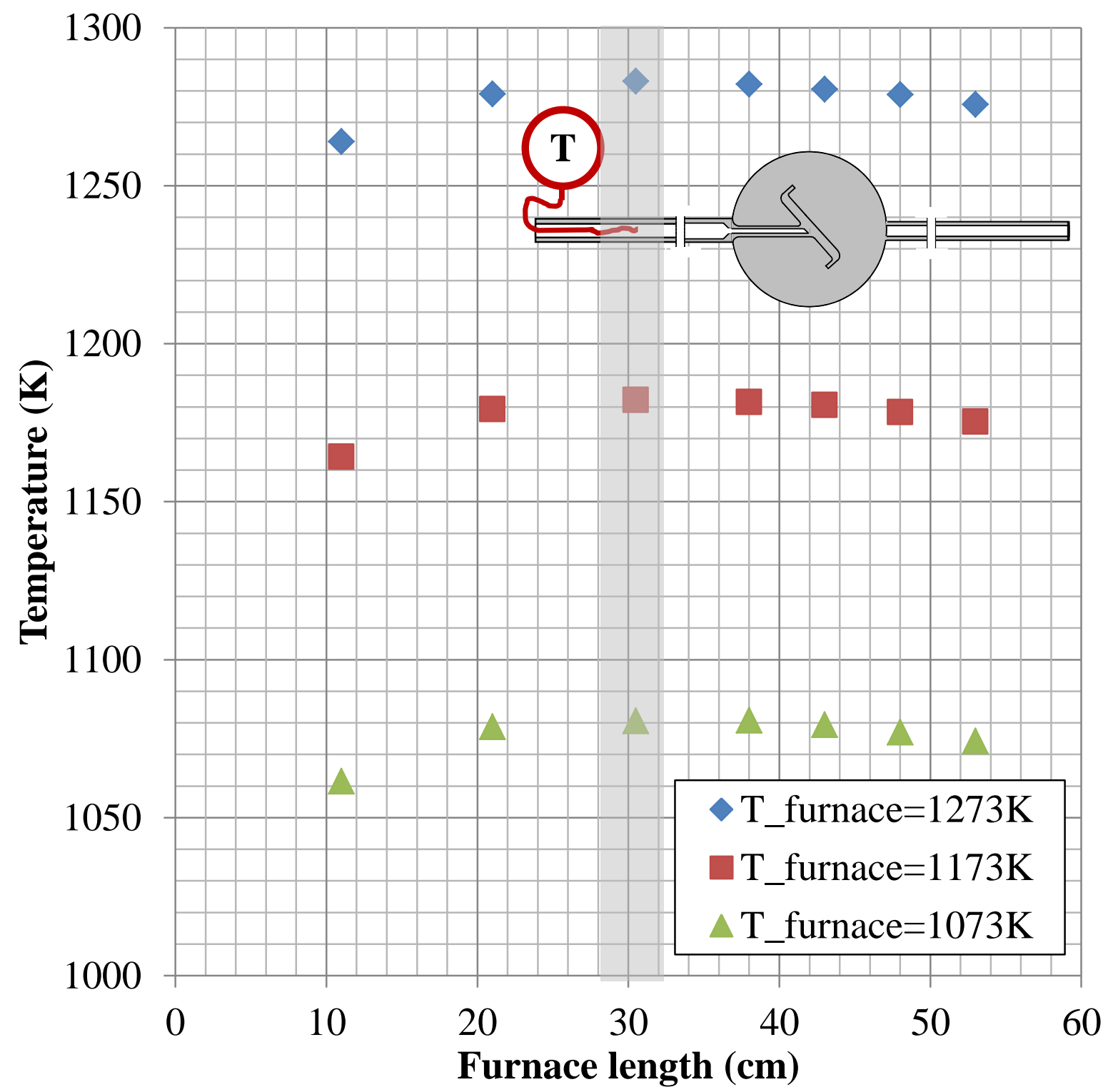

Figure 5: Longitudinal temperature furnace profile at different set point temperature - The gap is below $1 \%$. 


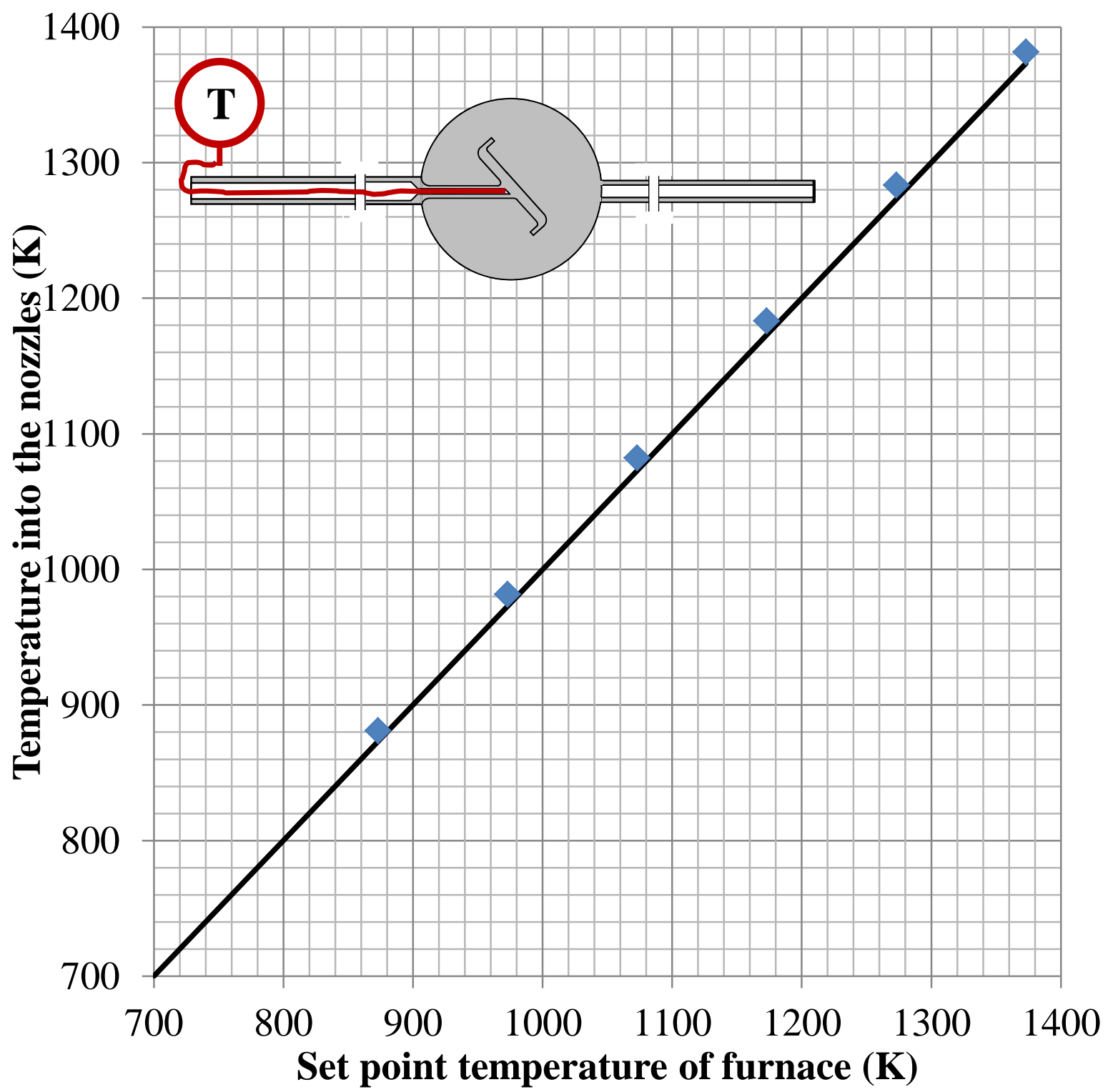

Figure 6: Several temperatures into the JSR (in the middle of four nozzles) according to set point temperature furnace - The gap is below $0.9 \%$.

\subsection{CFD simulations}

CFD has emerged as an effective tool for predicting flow behavior in various applications such as chemical reactors for combustion or pyrolysis. Here, only the reactor's hydrodynamic behavior was investigated. The reactor was designed. The temperature and absolute pressure applied were those measured during pyrolysis experiments and used to produce the kinetic model (Bensabath et al., 2016). A 3D model of the JSR was simulated using a commercial CFD code. All theoretical simulations were performed using the Workbench ${ }^{\circledR}$ software package; Design Modeler, Meshing 
and Fluent ${ }^{\circledR}$ were used to perform calculations based on the finite-volume method (Patankar, 1980). The RNG-k- $\varepsilon$ turbulence model was used in the computational model to take the turbulent flow into account (Yakhot et al., 1992).

The RNG-k- $\varepsilon$ turbulence model was used in the computational model to take both laminar and turbulent flow into account (Gil and Mocek, 2012; Patankar, 1980). The choice of RNG-k- $\varepsilon$ turbulence model depends on considerations such as the computational effort (the calculation time) and the physics in the flow. Indeed RNG-k- $\varepsilon$ model tends to take $10-15 \%$ more calculation time than the standard k- $\varepsilon$ model but it allows taking into account the turbulent viscosity while $\mathrm{k}-\varepsilon$ model is known to be used mostly to treat diffusivity phenomenal (Ansys, 2017). The RSM model is more appropriate because it uses a coupling between the Reynolds stresses and the mean flow. However it requires more calculation time than RNG-k- $\varepsilon$ model (40\%). Therefore RNG-k- $\varepsilon$ model was chosen. Furthermore the "Enhanced Wall Treatment" was employed with the RNG-k- $\varepsilon$ model with the intention of increasing the accurate results near nozzles and near-wall region.

A design of the gas volume considered for the calculations is presented in Figure 7.

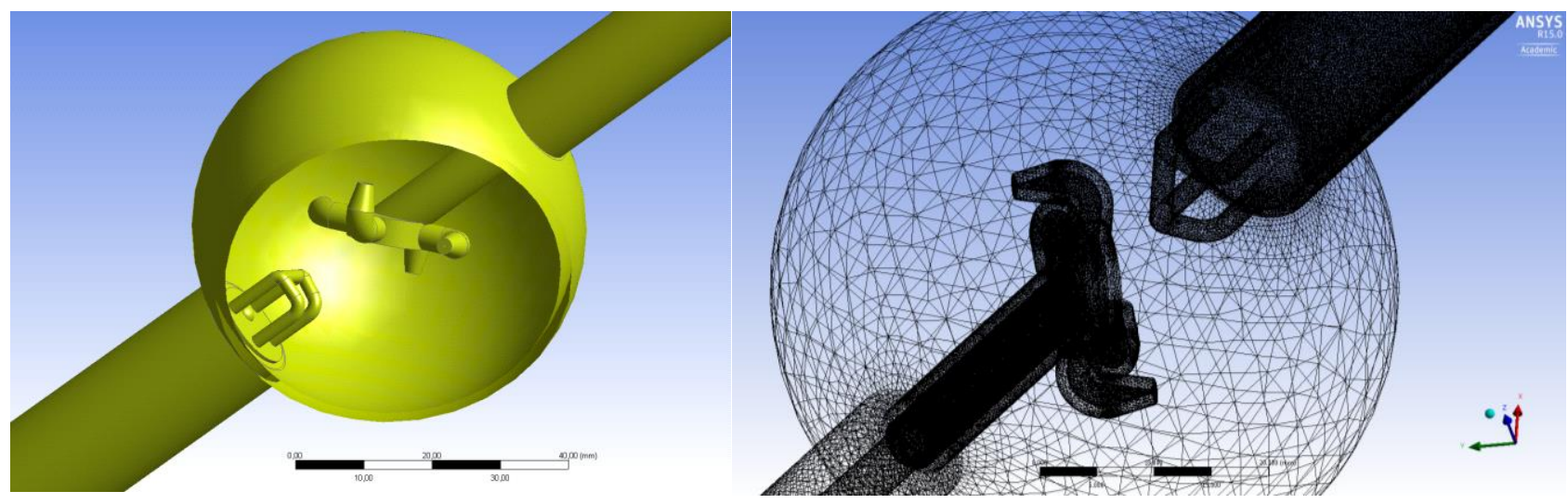

Figure 7: Design and mesh of the JSR produced using Design Modeler and Meshing software $\left(\right.$ ANSYS ${ }^{\circledR}$ ) - total elements: $10^{7}$ - pipes were composed of $10^{5}$ hexahedral mesh elements - the sphere structured grid was made-up of $10^{5}$ tetrahedral mesh elements - 100 mesh units for the outlet of nozzles's section - small mesh size of the four nozzles structure 
Simulations were performed at steady state regime to investigate Hinze and Van der Hegge Zijnen's hydrodynamic conditions (1949). As the computational time was sometimes very long, and for convenience, the inlet and outlet pipe were shortened. In addition to reducing computation times, these modifications to the geometry allow the hydrodynamics to be studied in the sphere alone. Simulations were performed for gas nitrogen of constant density (incompressible fluid assumption), under isothermal conditions and with negligible gravity. The influence of $\mathrm{P}$ and $\mathrm{T}$ on the dynamic viscosity and density of the fluid was considered when operating conditions were changed. Equations of continuity and momentum conservation balance were used and are listed below (Bird et al., 1960).

The equation of continuity is given by:

$$
\frac{D \rho}{D t}=-\rho(\nabla \vec{u})
$$

The Navier-Stokes's simplified equation was used:

$$
\rho \frac{D \vec{u}}{D t}=-\nabla P-\rho(\vec{u} \cdot \vec{\nabla}) \vec{u}+\mu \nabla^{2} \vec{u}
$$

To solve these equations, the boundary conditions assume no slip and no heat transfer through the walls between the inside and the outside of the reactor. The temperature was kept constant on the wall of the jet nozzles inside the sphere. The gas velocity was specified at the entrance to the reactor and the outlet pressure was set at the process pressure. The mesh of the reactor volume was composed of $10^{7}$ elements. Three connected regions were created: the inlet tube, the sphere with the four jet nozzles and the outlet tube. These regions corresponded to a combination of tetrahedral and hexahedral meshes. The grids for the inlet and outlet tubes were composed of $10^{5}$ hexahedral mesh elements. In the sphere, the structured grid was made-up of $10^{5}$ tetrahedral mesh elements. A very small mesh size must be used close to the jet nozzle to obtain accurate results, but cells must be large enough to limit their number near the wall of the sphere. Therefore, a gradient of mesh size was used. 
To examine the grid independency, the mean gas velocity was determined in different regions in the reactor at steady state for a number of grid resolutions. CFD results obtained with the use of fine and medium grids were almost identical. Therefore, the calculation time was reduced by using the medium grid. However, a fine mesh was still used close to jet nozzles, with 105 mesh units for the nozzle section $\left(0.07 \mathrm{~mm}^{2}\right)$.

\section{Results and discussion}

\subsection{Experimental results vs. kinetic model}

Experimental results were compared to those obtained by applying a detailed kinetic model (Bensabath et al., 2016). This model was developed to describe the formation of chemical compounds such as benzene, toluene and PAH during pyrolysis of light hydrocarbons in gas carburizing conditions, i.e., at low-pressure and high temperature. The model was validated against experimental data from the literature (Norinaga et al., 2006).

Light species quantified during pyrolysis of pure acetylene and kinetic simulations are presented in Figure 8. Graphs show how the molar fractions change as a function of the residence time in the reactor for acetylene, hydrogen, methane, ethylene, propyne, vinylacetylene, 1,3-butadiene, benzene and toluene. Acetylene predominated in all cases because it was never completely converted. Hydrogen was produced in large amount because $\mathrm{PAH}$ formation leads to an increase of the $\mathrm{C} / \mathrm{H}$ ratio by producing heavy products with concomitant $\mathrm{H}_{2}$ release. Methane, ethylene, vinylacetylene and benzene were also formed in important amounts. The decrease in acetylene and vinylacetylene concentrations with residence time can be explained by their consumption due to the HACA mechanism (Bensabath et al., 2016; Norinaga et al., 2006, 2009; Sánchez et al., 2012). A trend for increasing molar fractions for hydrogen, methane, ethylene and benzene with residence time was also observed. Nevertheless, it appears that species reach a maximum (except for hydrogen methane and ethylene) at long residence times (above $1 \mathrm{~s}$ for some species). 
Good agreement was observed between these experimental results and the results produced by the model. Particularly good agreement was obtained for acetylene, ethylene and benzene. In contrast, although similar orders of magnitude were recorded for the molar fractions of hydrogen, methane and vinylacetylene, a difference between experimental results and those produced by the model was noted. Thus, although the models of the literature represent quite well the experimental data, they require more investigations to explain, in particular, the evolution of the concentration of the methane obtained from unsaturated hydrocarbons. 

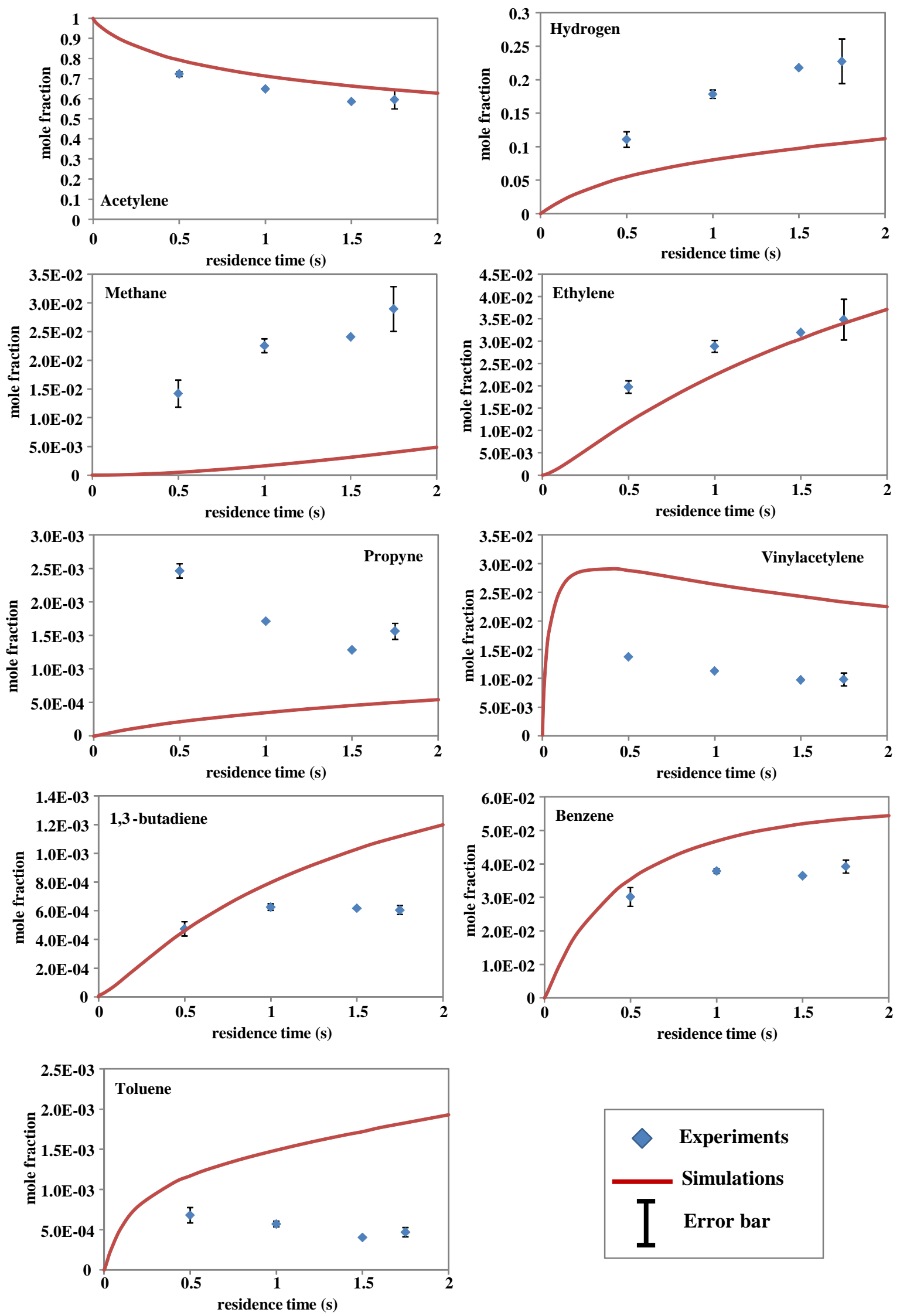

Figure 8: Molar fraction profiles of light species produced from pyrolysis with pure acetylene -

Comparison between experimental data and simulations ( $\bullet$ experiments, $\longrightarrow$ simulations, 
Bensabath et al., 2016) - T=1173 K, P=8 kPa - A trend for increasing molar fractions was observed when the molecular weight increases - the gap between experiments and kinetic model may be due to the perfect stirred reactor assumption used in the model (§4.2.).

\subsection{The three criteria for perfect mixing}

Conditions of ideal mixing in the reactor where the reactor is considered to display turbulent flow near the nozzle outlet, with a sufficient recycling rate and a jet velocity lower than the speed of sound were studied by CFD simulations. These studies showed the influence of temperature and pressure on the reactor's hydrodynamic behavior. Several residence times were tested. A temperature of $273 \mathrm{~K}$ and pressure of $101.3 \mathrm{kPa}$ were used to validate CFD simulations against Hinze's experimental data, whereas $1173 \mathrm{~K}$ and $8 \mathrm{kPa}$ were used to simulate the conditions prevailing during pyrolysis. 


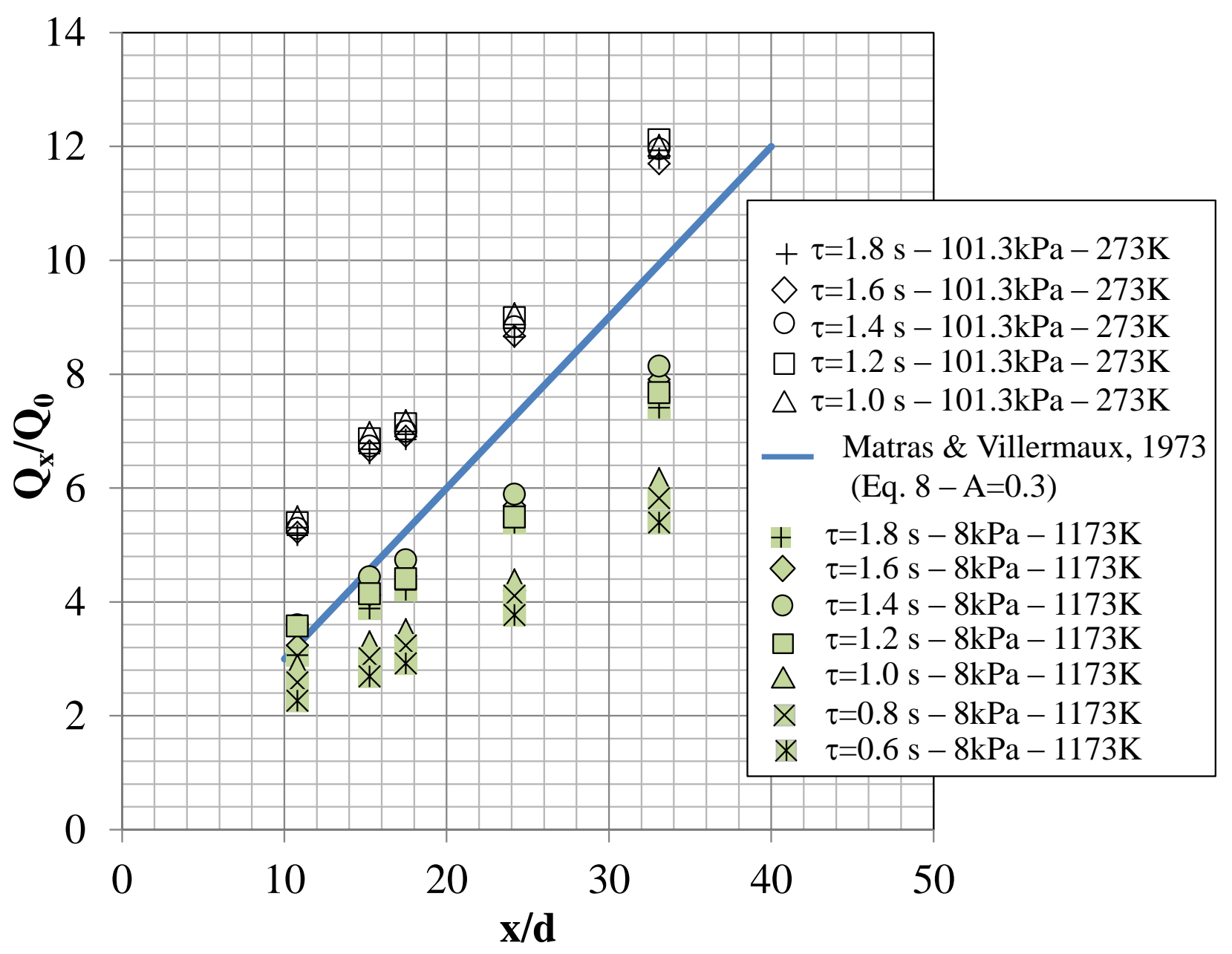

Figure 9: Gas flow rate distribution along the axis of the jet - theoretical linear curve (Eq. 8) corresponds uses a coefficient of 0.3 - good agreement with theory at $101.3 \mathrm{kPa}$ and $273 \mathrm{~K}$ (Hinze, and Van der Hegge Zijnen, 1949) but deviation observed at $8 \mathrm{kPa}$ and $1173 \mathrm{~K}$

\begin{tabular}{|l|c|c|c|c|c|c|c|}
\hline$\tau(\mathrm{s})$ & 0.6 & 0.8 & 1 & 1.2 & 1.4 & 1.6 & 1.8 \\
\hline $\mathrm{A} \mathrm{(-)}$ at $273 \mathrm{~K}$ and $101.3 \mathrm{kPa}$ & unozzle $>\mathrm{c}_{\text {sound }}$ & unozzle $>\mathrm{c}_{\text {sound }}$ & 0.39 & 0.39 & 0.38 & 0.37 & 0.38 \\
\hline $\mathrm{A} \mathrm{(-)}$ at $1173 \mathrm{~K}$ and $8 \mathrm{kPa}$ & 0.17 & 0.18 & 0.19 & 0.24 & 0.26 & 0.25 & 0.23 \\
\hline
\end{tabular}

Table 1: Value of the A parameter calculated by CFD simulation in two operating conditions according the residence time, $\tau$ (s): (i) $273 \mathrm{~K}$ and $101.3 \mathrm{kPa}$; (ii) $1173 \mathrm{~K}$ and $8 \mathrm{kPa}$

The volume flow rate, $\mathrm{Q}_{\mathrm{x}}$, was calculated through the section of the cone (Figure 3) at distance $\mathrm{x}$ for all simulations. Figure 9 shows an example of the distribution of the volume flow rate for the gas from the jet is shown as a function of distance from the nozzle. The theoretical linear curve Page 18 
corresponds to the resolution of equation 8 applying a coefficient of 0.3. Simulations corresponded quite well with theoretical calculations at $101.3 \mathrm{kPa}$ and $273 \mathrm{~K}$, although slight deviation remains visible, probably due to the accuracy of computation and the approximation applied during linearization of equation 4 . Indeed, at $273 \mathrm{~K}$ and $101.3 \mathrm{kPa}$, the mean for the A parameter is 0.38 (Table 1). The difference between this result and experimental data is $20 \%$, but the standard deviation calculated under various hydrodynamic conditions is less than $1 \%$ (Matras and Villermaux, 1973; Hinze, and Van der Hegge Zijnen, 1949). Simulations performed at 273 K and $101.3 \mathrm{kPa}$ thus adequately corroborate experiments for the residence times studied, and the simulations are therefore validated.

However, when applying conditions combining a vacuum $(8 \mathrm{kPa})$ and a high temperature (1173 K), the difference between simulations and experimental data increased to $28 \%$, and the deviation increased to $4 \%$ (Table 1). As a result, pressure and temperature affect the A parameter; indeed, several reports indicated that the value of the A parameter increases with temperature and decreases with pressure (Matras and Villermaux, 1973; David and Matras, 1975). This influence explains the disparities recorded here.

These A parameter values can be used to determine whether the geometric characteristics of our JSR ensure accurate operation of the device.

Figure 10 shows how the nozzle diameter would need to change depending on the reactor's radius to achieve a residence time of $1.8 \mathrm{~s}$ in order to fulfill criteria under different pressures and temperatures. The straight lines indicate that the three criteria reach a uniform gas phase composition corresponding to the free jet condition. Free jet theory can thus be used because the condition (Eq. 5) is satisfied (Liepmann and Laufer, 1947). A JSR is ideal if its operating conditions and its geometrical characteristics place it in the gray zone. This is the case for our reactor when operating at $273 \mathrm{~K}$ and $101.3 \mathrm{kPa}$. A similar result was found for a range of residence times, confirming that this JSR can be used in these operating conditions (David and Matras, 1975). 


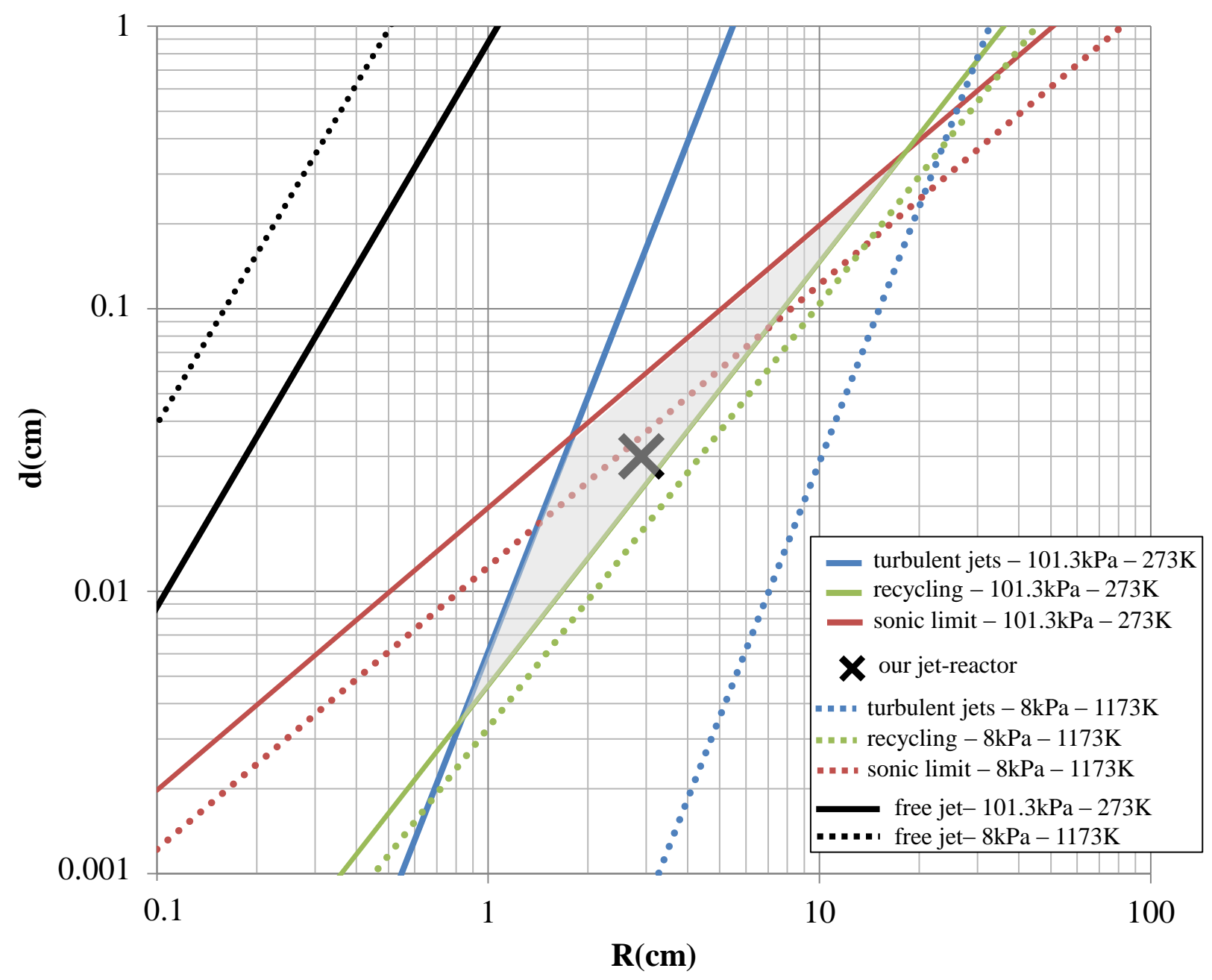

Figure 10: Ideal reactor operating area (gray region) defined by the three criteria (Eqs. 2-4) and the free jet condition (Eq. 5) (Liepmann and Laufer, 1947) - results of CFD simulation with air for $\tau=1.8 \mathrm{~s}$ at $1173 \mathrm{~K}, 8 \mathrm{kPa}$ and $273 \mathrm{~K}, 101.3 \mathrm{kPa}-\mathbf{X}$ our reactor - no ideal reactor area found for carburizing operations (vacuum pyrolysis) -validation of CFD calculation at $273 \mathrm{~K}, 101.3 \mathrm{kPa}$ thanks to the literature (Matras and Villermaux, 1973)

However, no ideal reactor operating could be found at $1173 \mathrm{~K}$ and $8 \mathrm{kPa}$. In these conditions, despite good mixing of the gas phase (the cross characterizing our JSR falls below the curve representing the recycling criterion) and a gas velocity at the nozzle outlet exceeding the speed of sound is required, the calculation therefore indicated a turbulence criterion in the linear equation 
which is incompatible with a turbulent jet from the nozzle. The suggested value of the jet Reynolds number (Eq.1) must be close to 800 (Matras and Villermaux, 1973). For a residence time of $1.8 \mathrm{~s}$, under pyrolysis conditions and at $101.3 \mathrm{kPa} / 273 \mathrm{~K}$, it is equal to 18 and 3358 , respectively. At $8 \mathrm{kPa}$ and $1173 \mathrm{~K}$, this value is close to 40 when the velocity reaches the speed of sound ( $\tau=0.6 \mathrm{~s})$, but remains well below the recommended Reynolds number.

The residence time decreases with increasing gas velocity at the outlet of the nozzle. The gas flow tends increasingly toward turbulence, and the gas velocity nears the upper limit. In pyrolysis conditions, the evolution of the three criteria with a residence time between $0.6 \mathrm{~s}$ and $1.8 \mathrm{~s}$ is illustrated in Figure 11. Whatever the residence time used in our experiments, internal mixing was never turbulent. Naturally, decreasing the residence time could allow turbulent mixing to be achieved. Nevertheless, a substantial increase in gas velocity at the nozzle outlet would be required, and consequently the speed of sound criterion would not be met. 


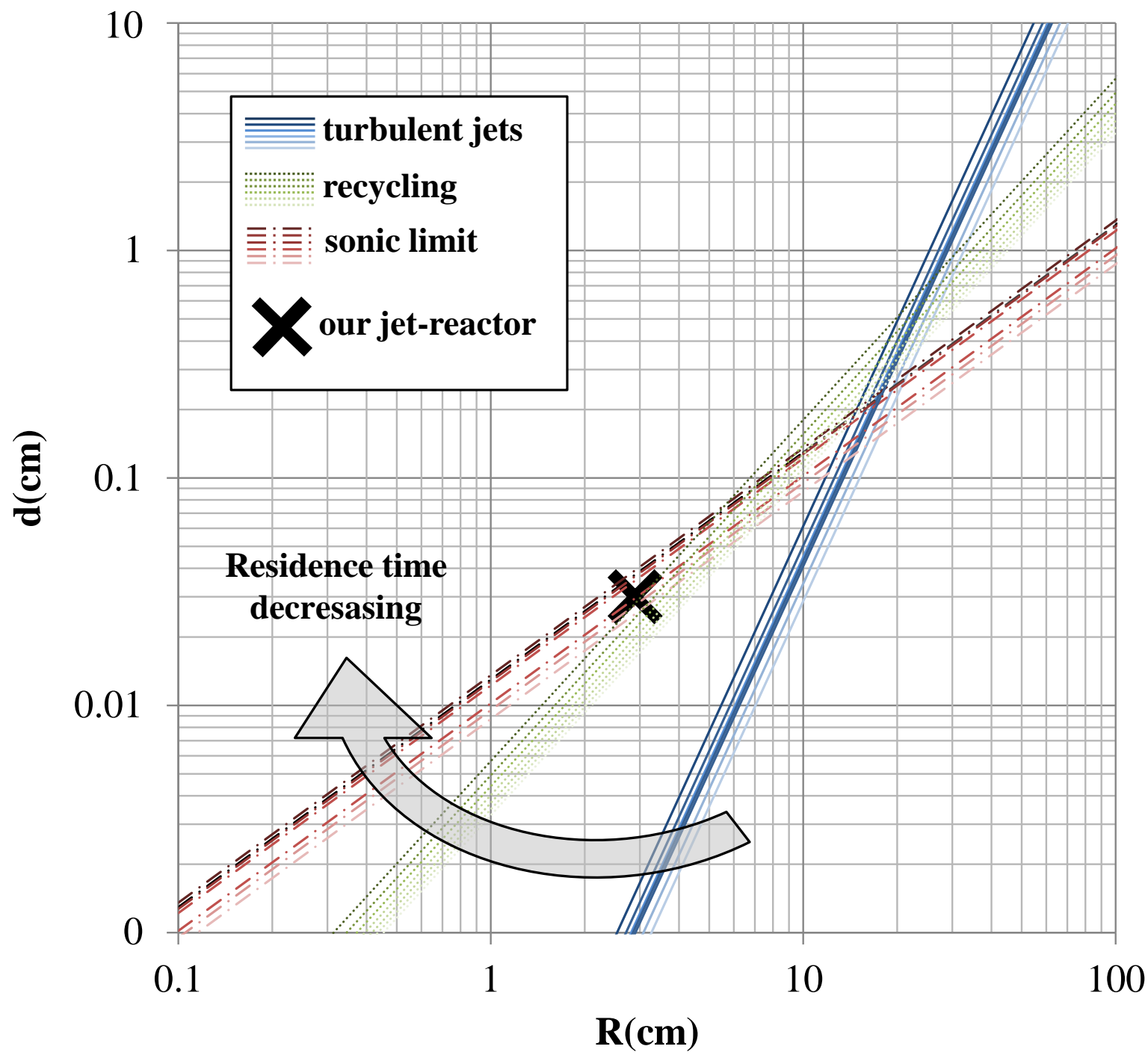

Figure 11: The three criteria (Eqs. 2-4) defined by results of CFD simulation with air for different residence times (Table 1) at $1173 \mathrm{~K}, 8 \mathrm{kPa}-\mathbf{X}$ our reactor - whatever the residence time no ideal area found for our JSR

However molecular diffusion is greatly enhanced at low pressure and, consequently, the axial dispersion within nozzles (Bird et al., 1960; Levenspiel, 1962). Therefore the assumption that the flow should necessarily be turbulent is not needed to achieve a Perfect Stirred Reactor condition.

4.3. The effects of the molecular diffusion and the diffusivity coefficient 
In one of the four nozzles supposed to be a pipe, the axial dispersion, $\mathrm{D}$, can be written by the sum of the two effects: dispersion by diffusion ( \) and dispersion by convection $\left(u^{2} d^{2} / 192 \varnothing^{2}\right)$ (Taylor, 1953, 1954; Aris, 1953; Levenspiel, 1962) (Eq. 11).

$$
D=\varnothing+\frac{u^{2} d^{2}}{192 \varnothing 2}
$$

The diffusivity coefficient, $(2)$, at low pressure can be estimated thanks to the equation 12 (Bird et al., 1960).

$$
\frac{P \bowtie(}{\left(P_{C_{2} \mathrm{H}_{2}}^{c} P_{N_{2}}^{c}\right)^{1 / 3}\left(T_{C_{2} H_{2}}^{c} T_{N_{2}}^{c}\right)^{5 / 12}\left(\frac{1}{M_{C_{2} H_{2}}}+\frac{1}{M_{N_{2}}}\right)^{1 / 2}}=a\left(\frac{T}{\sqrt{T_{C_{2} H_{2}}^{c} T_{N_{2}}^{c}}}\right)^{b}
$$

in which $P^{c}$ and $T^{c}$ are the critical pressure (atm) and temperature $(\mathrm{K})$, respectively. For non-polar gas-pairs, the values of the constants a and b are following (Bird et al., 1960):

$$
\mathrm{a}=2.74810^{-4}
$$

$b=1.823$

Figure 12 shows the evolution of the diffusivity coefficient of acetylene in nitrogen as a function of the pressure. It is equal to $0.23 \mathrm{~cm}^{2} / \mathrm{s}$ and $35.53 \mathrm{~cm}^{2} / \mathrm{s}$ at $101.3 \mathrm{kPa}-273 \mathrm{~K}(\mathrm{~W})$ and $8 \mathrm{kPa}-1173 \mathrm{~K}$ (ఓ) respectively. The ratio between two operating conditions is close to 157 and shows the significant increase of the diffusivity when the pressure decreases. 


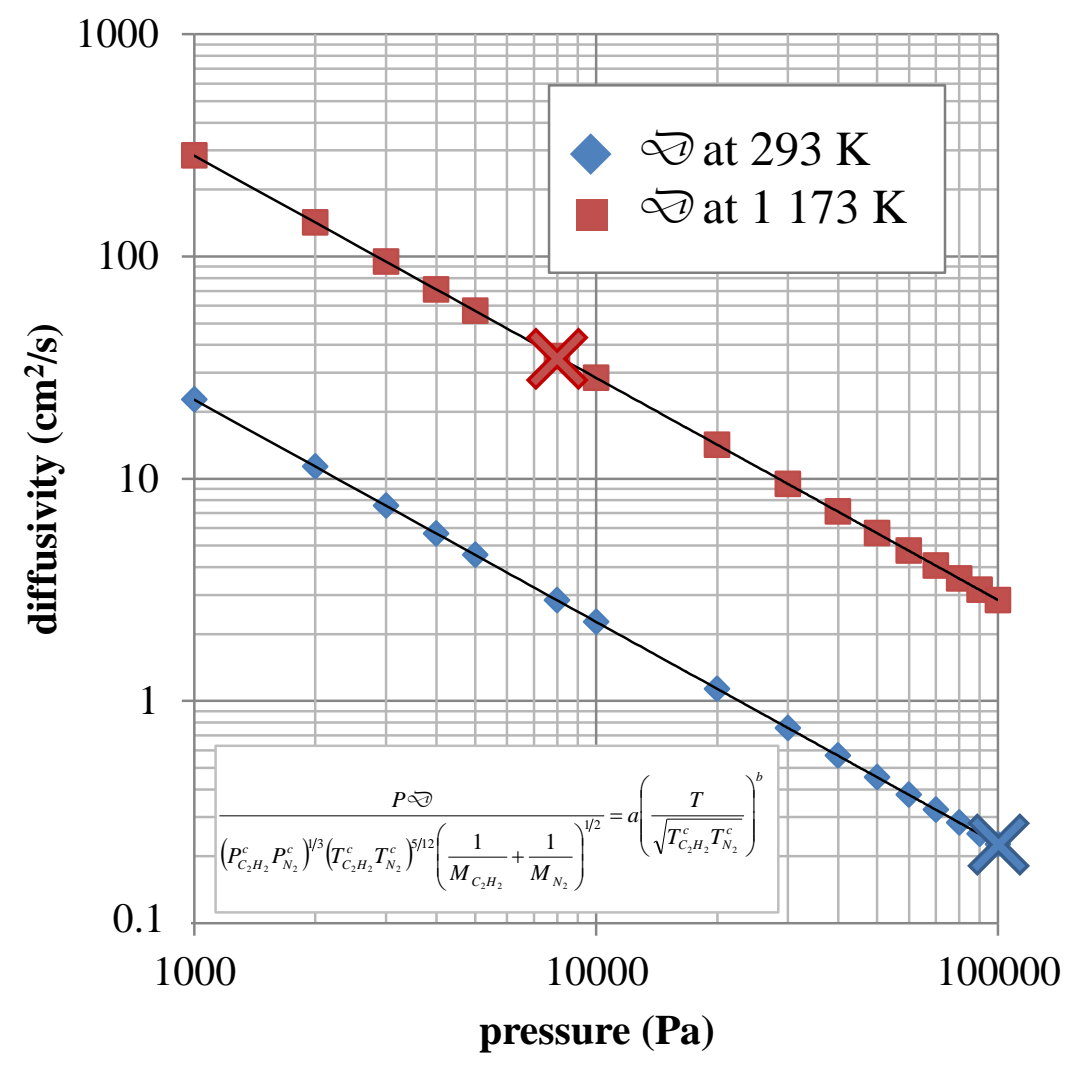

Figure 12: Estimation of acetylene diffusivity at low pressures in nitrogen thanks to the kinetic theory (Bird et al., 1960) - T=293 K and $1173 \mathrm{~K}$ - Comparison between two operating conditions,

$$
293 \mathrm{~K}-101.3 \mathrm{kPa}(\boldsymbol{\aleph}) \text { and } 1173 \mathrm{~K}-8 \mathrm{kPa}(\boldsymbol{\aleph})
$$

This relationship 12 can be written as following (Eq. 13):

$\frac{D}{u d}=\frac{\grave{\varnothing}}{u d}+\frac{u d}{192 ळ}$

In our case, values of $u d / \infty$ which is the product of the Reynolds and Schmidt numbers (Eqs. 14, 15) are very low (Table 2).

$$
\begin{aligned}
& \operatorname{Re}_{n o z z l e} \times S c=\frac{\rho u d}{\mu} \times \frac{\mu}{\rho \overline{(D)}}=\frac{u d}{\overline{(D)}} \\
& S c=\frac{\mu}{\rho \overline{(D)}}
\end{aligned}
$$


This factor ranges between 14 and 43 (Table 2). It is due to on the one hand the low value of the Reynolds number (in these operating conditions the gas flow is laminar) calculated in one of four nozzles supposed to be a pipe and the other the high value of molecular diffusion.

\begin{tabular}{|c|c|c|c|c|}
\hline$\tau(\mathrm{s})$ & $\mathrm{u}(\mathrm{m} / \mathrm{s})$ & $\operatorname{Re}_{\text {nozzle }}$ (Eq. 14) & Sc (Eq. 15) & $\operatorname{Re}_{\text {nozzle }} \times S c$ \\
\hline 1.8 (max value) & 173 & 23 & 0.61 & 14 \\
\hline 0.6 (min value) & 510 & 71 & 0.61 & 43 \\
\hline
\end{tabular}

Table 2: Experimental values of Reynolds and Schmidt number for minimum et maximum residence time $-\mathrm{T}=1173 \mathrm{~K}$ and $\mathrm{P}=8 \mathrm{kPa}-\rho_{\text {acetylene }}=0.0213 \mathrm{~kg} / \mathrm{m}^{3}$ calculated thanks to the ideal gas equation - $\mathrm{u}$, the gas velocity $(173<\mathrm{u}(\mathrm{m} / \mathrm{s})<510)-\mathrm{d}$, the nozzle diameter $(300 \mu m)-\mu$, the acetylene dynamic viscosity equal to $4.6310^{-5} \mathrm{~Pa} . \mathrm{s}$ at $1173 \mathrm{~K}$ and $8 \mathrm{kPa}$.

Figure 13 shows $\mathrm{D} / \mathrm{ud}$ plotted against $\operatorname{Re}_{\text {nozzle }} \times S c$, representing relation 303 . The figure 302 can be divided into two sections by the black line which corresponds to the minimum of the dispersion number (D/ud) obtained for $\operatorname{Re}_{n o z z l e} \times S c$ close to 15 .

1. Above $\operatorname{Re}_{n o z z l e} \times S c=15$, the axial dispersion is large and hence the flow is mixed thanks to the convection.

2. Close to $\operatorname{Re}_{n o z z l} \times S c=15$, The axial dispersion is negligible and the mixing is low (plug flow regime).

3. Below $\operatorname{Re}_{n o z z l e} \times S c=15$, the axial dispersion can be large thanks to the high value of molecular diffusion.

The figure 13 shows that our operating conditions (gray zone) are close to the minimum of dispersion number. Indeed, despite the high value of the molecular diffusion which has a strongly effect on the rate of axial dispersion in laminar flow, the convection is not sufficiently important to neglect it (Levenspiel, 1962). 


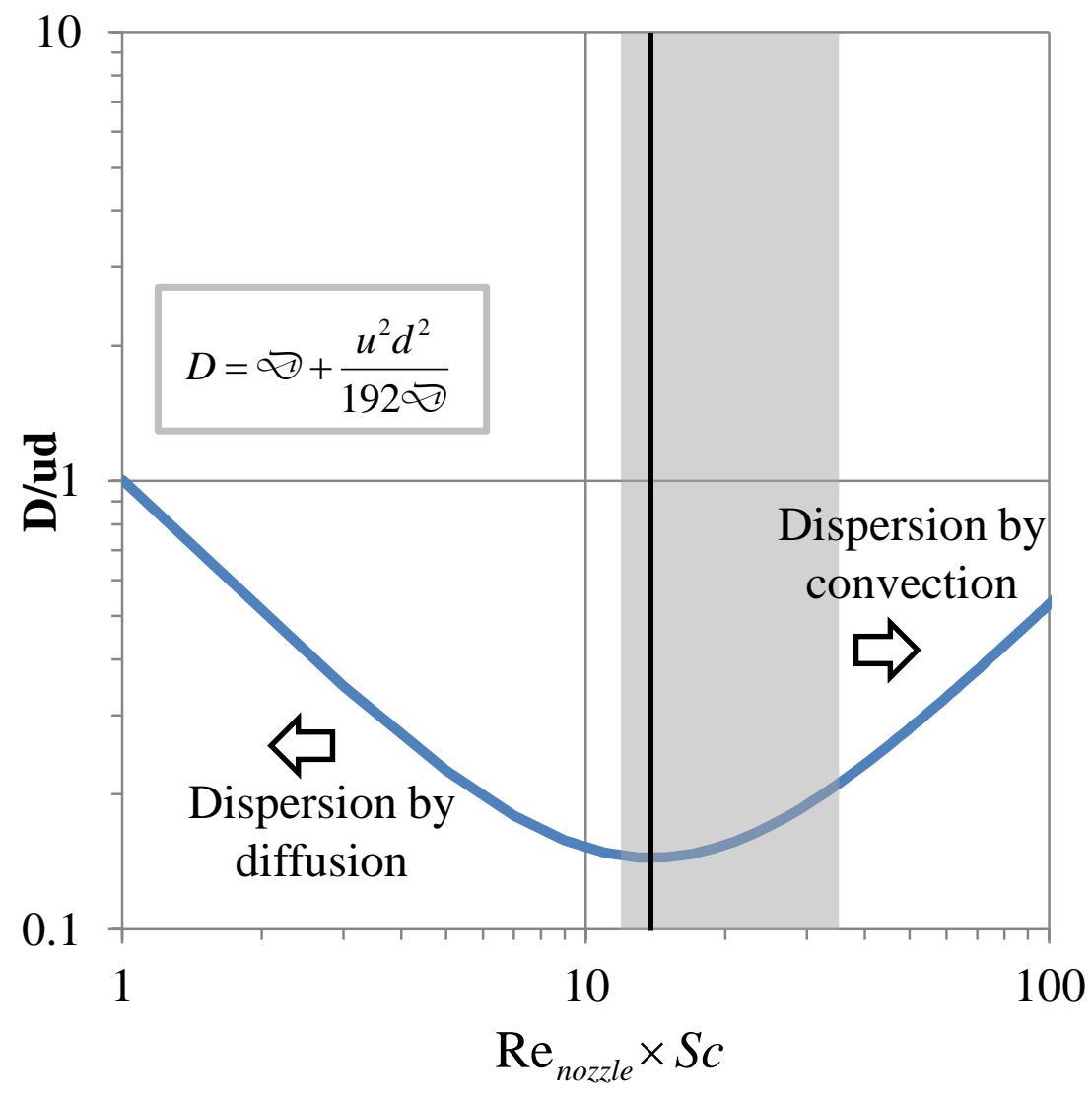

Figure 13: Axial dispersion in a pipe (Levenspiel, 1962) - the vertical black line is the limit between the dispersion by diffusion and by convection - the gray zone indicates the operating zone of our JSR.

In spite of the high value of $\varpi$, which is inversely proportional to the pressure and increases with increasing temperature it is not sufficient to offset the low value of Reynolds number mainly due to the low gas density. Hence in the four nozzles the axial dispersion is negligible and the hydrodynamic regime can be supposed to be plug flow. These calculations allow understanding both the lack of turbulence in four nozzles and the too low value of diffusivity to reach a perfect mixing in the sphere.

\section{Conclusions}

Acetylene pyrolysis was studied (experiments and modeling thanks to a detailed kinetic model) in conditions close to those encountered in low-pressure gas carburizing furnaces, at $1173 \mathrm{~K}, 8 \mathrm{kPa}$ 
and under pure acetylene. Experiments were performed in a spherical quartz continuous gas-jet reactor, the hydrodynamics of which were investigated using CFD simulations. In particular, variations in the hydrodynamic conditions depending on $\mathrm{T}$ and $\mathrm{P}$ were examined, assuming a perfectly mixed. The aim was to discuss the flow model used in the Chemkin ${ }^{\circledR}$ software (perfectly stirred reactor) to model the pyrolysis reaction was based on appropriate assumptions.

At the outlet from the reaction zone, light pyrolysis products $\left(<\mathrm{C}_{7}\right)$ were analyzed on-line by gas chromatography (thermal conductivity detector (TCD) and flame ionization detector (FID)). Influence of residence time (between 0.5 and $1.75 \mathrm{~s}$ ) on the amounts of various chemical compounds was studied, and the model agreed well with experimental data for the reactant and the main products. However, some differences are observed for heavier products. These differences depend on several parameters such as analysis method or the difference between ideal hydrodynamic conditions and the experimental conditions in the JSR used. The assumptions made on the hydrodynamics of the reactor partly explain the discrepancies recorded.

Indeed the hydrodynamic CFD simulations appeared to indicate a lack of turbulence within the reactor; turbulence is essential for the perfectly stirred reactor assumption. This finding may be due to the recommended value of the Reynolds number, which is not suitable for low pressure conditions. Otherwise in spite of the high value of acetylene molecular diffusion, which is inversely proportional to the pressure and increases with increasing temperature it is not sufficient to offset the low value of Reynolds number.

The reactor may then be not really a perfectly stirred reactor. Despite these limitations, this assumption was used to simulate experimental results. The shift of the reactor from ideality may change results slightly but trends and orders of magnitude remain comparable. Further investigation will allow in the future to characterize the actual reactor and to simulate the flow more accurately. The presence of dead zones or short circuits which must be studied by determining Residence Time Distribution. In parallel, the influence of temperature and pressure on the A parameter will be 
investigated. The nature of the gas used, such as acetylene, will have little impact on the value of the A parameter as its density, viscosity and molar mass are very similar to those of air.

The model must be improved: some reaction pathways are still missing or wrongly evaluated, and hydrodynamic conditions need to be taken into account. To decrease occupational risk for workers exposed to by-products of carburization, further experiments are planned, with an iron piece placed in the reactor. These experiments will allow us to investigate the influence of surface reactions on the generation of gaseous compounds like benzene.

In the future, the kinetic model developed by Bensabath et al., 2016 and implemented in Chemkin ${ }^{\circledR}$ Software for PAH formation during acetylene pyrolysis will be included in the Ansys ${ }^{\circledR}$ Fluent ${ }^{\circledR}$ CFD code. Other aspects will also be studied with CFD, such as the influence of geometric furnace parameters on the generation of benzene, PAHs or soot (Violi et al., 1999; Kuwana et al., 2006).

\section{References}

Adeosun, J.T., Lawal, A., 2009. Numerical and experimental studies of mixing characteristics in a T-junction microchannel using residence-time distribution. Chemical Engineering Science, 64, Issue 10, 2422-2432. doi.org/10.1016/j.ces.2009.02.013.

ANSYS Fluent Getting Started Guide Release 18.0 January 2017, ANSYS, Inc. and ANSYS Europe, Ltd. are UL registered ISO 9001: 2008 companies.

Ayass, W.W., Nasir, E.F., Farooq, F. A., Sarathy, S.M., 2016. Mixing-structure relationship in jetstirred reactors. Chemical Engineering Research and Design, 111, 461-464. doi: 10.1016/j.cherd.2016.05.016

Azay, P., Côme, G.M., 1979, Temperature gradients in a continuous flow stirred tank reactor. Ind. Eng. Chem. Process Des. Dev., 18, 754-756. 
Bensabath, T., 2017. Approche préventive pour une réduction des Hydrocarbures Aromatiques Polycycliques (HAP) dans les fours à pyrolyse - Application à la cémentation gazeuse à basse pression. Thesis Lorraine University France. https://tel.archives-ouvertes.fr/tel-01710271.

Bensabath, T., Monnier, H., Glaude, P-A., 2016. Detailed kinetic modeling of the formation of toxic Polycyclic Aromatic Hydrocarbons (PAHs) coming from pyrolysis in low-pressure gas carburizing conditions. Journal of Analytical and Applied Pyrolysis, 122, 342-354. doi.org/10.1016/j.jaap.2016.09.007.

Bird, R.B., Stewart, W.E., Lightfoot, E.N., 1960. Transport Phenomena. Chemical Engineering Department. University of Wisconsin-Madison. John Wiley \& Sons, Inc. New York.

Bush, S.F., 1969. The design and operation of single-phase jet-stirred reactors for chemical kinetic studies. Trans. Inst. Chem. Eng., 47, 59-72.

Champmartin, C. Jeandel, F. Monnier, H., 2017. Maintenance of low-pressure carburizing furnaces: a source of PAH exposure. Ann. Work Expo. Health, 61, 321-332. https://doi.org/10.1093/annweh/wxw024.

Commenge, J-M., Obein, T., Genin, G., Framboisier, X., Rode, S., Schanen, V., Pitiot, P., Matlosz, M., 2006.Gas-phase residence time distribution in a falling-film microreactor. Chemical Engineering Science, 61, Issue 2, 597-604. doi.org/10.1016/j.ces.2005.07.015.

Dai., B., Fan, Y., Yang, J., Xiao, J., 1999. Effect of radicals recombination on acetylene yield in process of coal pyrolysis by hydrogen plasma. Chemical Engineering Science, 54, Issue 7, 957-959. https://doi.org/10.1016/S0009-2509(98)00312-1.

David, R., Matras, D., 1975. Règles de construction et d'extrapolation des réacteurs auto-agités par jets gazeux. The Canadian Journal of Chem. Eng., 53, 297-300.

Dulcy, J., Gantois, M., 2007. Théorie des traitements thermochimiques - Cémentation. Carburation. Tech. Ing., M1222. 
Gavi, E., Marchisio, D.L., Barresi, A.A., 2007. CFD modelling and scale-up of Confined Impinging Jet Reactors. Chemical Engineering Science, 62, Issue 8, 2228-2241. doi.org/10.1016/j.ces.2006.12.077.

Gil I. Mocek P., 2012. CFD analysis of mixing intensity in jet stirred reactors, Chemical and Process Engineering, 33 (3) 397-410. doi: 10.2478/v10176-012-0035-9.

Herbinet, O. Dayma, G., 2013. Jet-Stirred Reactors. In Battin-Leclerc, F., Simmie, J.M., and Blurock E., Cleaner Combustion: Developing Detailed Chemical Kinetic Models, Springer, 183210, Green Energy and Technology 978-1-4471-5306-1 <10.1007/978-1-4471-5307-8>. https://hal.archives-ouvertes.fr/hal-00880195.

Herbinet, O., Husson B., Le Gall, H., Battin-Leclerc, F., 2015. Comparison study of the gas-phase oxidation of alkylbenzenes and alkylcyclohexanes. Chemical Engineering Science, 131, 49-62. doi.org/10.1016/j.ces.2015.03.026

Hiep, T.V., Kaliaguine, S., 1973. Etude cinétique de la réaction de carburation du molybdène par le méthane. Chemical Engineering Science, 28, Issue 11, 1951-1960. doi.org/10.1016/00092509(73)85039-0.

Hilgers, A., Boersma, B.J., 2001. Optimization of turbulent jet mixing. Fluid Dynamics Research. 29, 6, 345-368. doi.org/10.1016/S0169-5983(01)00035-1

Hinze, J.O. Van Der Hegge Zijnen, B.G., 1949. Transfer of heat and matter in the turbulent mixing zone of an axially symmetrical jet. Appl. Sci. Res., A1, 435-461.

Hognona, C., Simon, Y., Marquaire, P-M., Courson, C., Kiennemann, A., 2018. Hydrogen production by catalytic partial oxidation of propane over $\mathrm{CeO}$. Chemical Engineering Science, 181, 46-57. doi.org/10.1016/j.ces.2018.01.038

IARC-Monography, 2012. Monographs on Chemical agents and related occupations - A review of human carcinogens. 100F. 
Iwata, H., 2005. Advanced acetylene vacuum carburizing. IHI Eng. Rev. 38, 83-88.

Kanaris, A.G., Mouza, A.A., 2011. Numerical investigation of the effect of geometrical parameters on the performance of a micro-reactor. Chemical Engineering Science, 66, Issue 21, 5366-5373. doi.org/10.1016/j.ces.2011.07.044.

Kuwana, K., Li, T., Saito, K., 2006. Gas-phase reactions during CVD synthesis of carbon nanotubes: Insights via numerical experiments. Chemical Engineering Science, 61, Issue 20, 67186726. doi.org/10.1016/j.ces.2006.07.006.

Levenspiel, O., 1962. Chemical Reaction Engineering. Wiley John \& Sons. ISBN 10 : 047125424X ISBN $13: 9780471254249$

Liepmann, H.W., Laufer, J., 1947. Investigations of free turbulent mixing. NACA Tech. Note 1257, Natl. Advis. Comm. Aeronaut., Washington DC.

Matras, D., Villermaux, J., 1973. Un réacteur continu parfaitement agité par jets gazeux pour l'étude cinétique de réactions chimiques rapides. Chemical Engineering Science, 28 (1), 129-137.

Norinaga, K., Deutschmann, O., Hüttinger, K.J., 2006. Analysis of gas phase compounds in chemical vapor deposition of carbon from light hydrocarbons. Carbon, 44 (9), 1790-1800. doi.org/10.1016/j.carbon.2005.12.050.

Norinaga, K., Deutschmann, O., Saegusa, N., Hayashi, J-I., 2009. Analysis of pyrolysis products from light hydrocarbons and kinetic modeling for growth of polycyclic aromatic hydrocarbons with detailed chemistry. Journal of Analytical and Applied Pyrolysis, 86 (1), 148-160. doi.org/10.1016/j.jaap.2009.05.001.

Patankar, S., 1980. Numerical heat transfer and fluid flow. By CRC Press Textbook. ISBN 9780891165224 - CAT\# RT5223. 
Rota, R., Bonini, F., Servida, A., Morbidelli, M., Carrà, S., 1994. Analysis of detailed kinetic schemes for combustion processes: Application to a methane-ethane mixture. Chemical Engineering Science, 49, Issue 24, Part A, 4211-4221. doi.org/10.1016/S0009-2509(05)80016-8

Sánchez, N.E., Callejas, A., Millera, Á., Bilbao, R., Alzueta, M.U., 2012. Polycyclic aromatic hydrocarbon $(\mathrm{PAH})$ and soot formation in the pyrolysis of acetylene and ethylene: effect of the reaction temperature. Energy \& Fuels, 26 (8), 4823-4829. doi.org.10.1021/ef300749.

Toraño, J., Torno, S., Menendez, M., Gent, M., Velasco., J., 2009. Models of methane behaviour in auxiliary ventilation of underground coal mining. International Journal of Coal Geology. 80, 1, 3543. doi.org/10.1016/j.coal.2009.07.008

Violi, A., D’Anna, A., D’Alessio, A., 1999. Modeling of particulate formation in combustion and pyrolysis. Chemical Engineering Science, 54, Issues 15-16, 3433-3442. doi.org/10.1016/S00092509(98)00460-6.

Woldemariam, M., Filimonov, R., Purtonen, T., Sorvari, J., Koiranen, T., Eskelinen, H., 2016. Mixing performance evaluation of additive manufactured milli-scale reactors. Chemical Engineering Science, 152, 26-34. doi.org/10.1016/j.ces.2016.05.030.

Yakhot, V., Orszag, S.A., Thangam, S., Gatski, T.B., Speziale, C.G., 1992. Development of turbulence models for shear flows by a double expansion technique. Physics of Fluids A., 4 (7), 1510-1520. doi.org/10.1063/1.858424.

Yan, B., Xu, P., Jin, Y., Cheng, Y., 2012. Understanding coal/hydrocarbons pyrolysis in thermal plasma reactors by thermodynamic analysis. Chemical Engineering Science, 84, 31-39. doi.org/10.1016/j.ces.2012.08.005. 


\section{Nomenclature}

a, b constants for Eq. 12 (Bird et al., 1960)

A

adimensionnal parameter

csound

speed of sound

$\mathrm{m} / \mathrm{s}$

d

diameter of a nozzle in the JSR

m

$\mathrm{D}$

diffusivity coefficient

$\mathrm{m}^{2} / \mathrm{s}$

(2)

molecular diffusion

$\mathrm{m}^{2} / \mathrm{s}$

$\mathrm{k}$

kinetic energy

J

$\mathrm{P}$

pressure

$\mathrm{Pa}$

$\mathrm{P}^{\mathrm{c}}$

critical pressure

$\mathrm{Pa}$

Q

volume flow rate from the outlet of a nozzle

$\mathrm{m}^{3} / \mathrm{s}$

$\mathrm{R}$

radius of the sphere (JSR)

$\mathrm{m}$

$\operatorname{Re}$

Reynolds number

Snozzle

outlet of nozzle's section

$\mathrm{m}^{2}$

Sc Schmidt number

$\mathrm{t}$

time

$\mathrm{T}$

temperature

K

$\mathrm{T}^{\mathrm{c}}$

critical temperature

K

$\mathbf{u} 0$

velocity of the gas at the outlet of a nozzle in the JSR

$\mathrm{m} / \mathrm{s}$

$\mathrm{u}_{\mathrm{x}}$ axial velocity of the gas at $\mathrm{x}$-distance from the outlet of nozzle in the JSR m/s

$\overrightarrow{\mathrm{u}}$

velocity vector

$\mathrm{m} / \mathrm{s}$

V

volume of the JSR

$\mathrm{m}^{3}$

$\mathrm{X}$

axial distance from a nozzle in the JSR

$\mathrm{m}$ 
$\beta \quad$ angle of the cone formed by the jet

$\varepsilon$

dissipation energy

$\mu$

dynamic viscosity of the gas

Pa.s

$\rho$

density of the gas

$\mathrm{kg} / \mathrm{m}^{3}$

$\tau$

residence time of the gas in the JSR

S

Acronyms

CFD computational fluid dynamics

$\mathrm{BaP} \quad$ benzo[a]pyrene

FID flame ionization detector

FRC flow rate controller

GC gas chromatograph

IARC International Agency for Research on Cancer

JSR Jet-Stirred-Reactor

PAH Polycyclic Aromatic Hydrocarbon

RNG Re-Normalization Group methods developed by Yakhot et al., 1992

TCD thermal conductivity detector 